Check for updates

Cite this: RSC Adv., 2019, 9, 39532

Received 17th September 2019

Accepted 24th November 2019

DOI: 10.1039/c9ra07517h

rsc.li/rsc-advances

\title{
A novel ratiometric fluorescent probe for rapid detection of hydrogen peroxide in living cells $\dagger$
}

\author{
Linan $\mathrm{Hu}^{\text {ac }}$ Jiayi Liu, ${ }^{\mathrm{a}}$ Jie Zhang, ${ }^{\mathrm{a}}$ Hailiang Zhang, ${ }^{\mathrm{b}}$ Pengfei Xu, (D) ${ }^{* \mathrm{~b}}$ Zhu Chen $^{\star a}$ \\ and Enhua Xiao*a
}

In this work, we present a new ratiometric fluorescent probe JNY-1 for rapid and convenient detection of $\mathrm{H}_{2} \mathrm{O}_{2}$. The probe could selectively and sensitively respond to $\mathrm{H}_{2} \mathrm{O}_{2}$ within $10 \mathrm{~min}$. In addition, this probe was successfully applied for monitoring and imaging of $\mathrm{H}_{2} \mathrm{O}_{2}$ in liver cancer HepG2 cells under physiological conditions.

\section{Introduction}

Reactive oxygen species (ROS) is a collective term that describes the chemical species that are formed upon incomplete reduction of oxygen and includes the hypochlorous acid/hypochlorite ions $\left(\mathrm{HOCl} /{ }^{-} \mathrm{OCl}\right)$, hydrogen peroxide $\left(\mathrm{H}_{2} \mathrm{O}_{2}\right)$, superoxide anion $\left(\mathrm{O}^{2-}\right)$ and the hydroxyl radical $\left(\mathrm{HO}^{\circ}\right)$. ROS in the body are generated endogenously from oxygen mainly through the mitochondrial respiration process as well as exogenously by exposure to deleterious conditions including UV light, xenobiotics and infectious agents. ${ }^{1}$ ROS are classically known as indicators of oxidative stress, which is a fundamental process that operates in a diverse array of human diseases, including Alzheimer's diseases, cardiovascular disorders, and cancer. ${ }^{2-4}$ Hydrogen peroxide $\left(\mathrm{H}_{2} \mathrm{O}_{2}\right)$ is one of the most important ROS. Cellular hydrogen peroxide $\left(\mathrm{H}_{2} \mathrm{O}_{2}\right)$ arises primarily as a ubiquitous dismutation product of superoxide. Mounting evidence suggests that $\mathrm{H}_{2} \mathrm{O}_{2}$ production drives a broad spectrum of cellular processes. For example, when $\mathrm{H}_{2} \mathrm{O}_{2}$ is generated at low concentrations $(<0.7 \mu \mathrm{M})$ in a regulated fashion, it functions as a ubiquitous intracellular second messenger, regulating a multitude of physiological and pathological processes in cell. ${ }^{5}$ Under conditions of stress or stimulation by exogenous chemicals, $\mathrm{H}_{2} \mathrm{O}_{2}$ can be generated aberrantly and can be converted to dramatically more "damaging" ROS such as hypochlorous acid (HOCl) and hydroxyl radical ( $\left.\mathrm{HO}^{\circ}\right)$ by myeloperoxidase and Fenton reagents, respectively. The resulting ROS can attack cellular structures or biomolecules such as proteins, liposomes, and DNA, which has been associated with aging, Alzheimer's

${ }^{a}$ Departments of Radiology, The Second Xiangya Hospital, Central South University, Changsha, Hunan 410011, P. R. China

${ }^{b}$ Institute of Clinical Pharmacy \& Pharmacology, Jining First People's Hospital, Jining Medical University, Jining 272000, P. R. China

${ }^{c}$ Departments of Radiology, Zhuzhou Central Hospital, Zhuzhou, Hunan 412000, P. R. China

$\dagger$ Electronic supplementary information (ESI) available. See DOI: 10.1039/c9ra07517h disease, and cancer. ${ }^{6,7}$ However, the transient increase of intracellular $\mathrm{H}_{2} \mathrm{O}_{2}$ may be necessary for mitosis. ${ }^{8}$ Therefore, development of a rapid and highly selective method for monitoring $\mathrm{H}_{2} \mathrm{O}_{2}$ level change $\mathrm{H}_{2} \mathrm{O}_{2}$ in living cells is of great significance.

However, it is challenging to capture and detect $\mathrm{H}_{2} \mathrm{O}_{2}$ in living cells. This is mainly due to $\mathrm{H}_{2} \mathrm{O}_{2}$ in the cells possessing the following characteristics. At first, $\mathrm{H}_{2} \mathrm{O}_{2}$ can readily moves out of cells through free diffusion. So, it's difficult to detect intracellular $\mathrm{H}_{2} \mathrm{O}_{2}$ in situ. Second, $\mathrm{H}_{2} \mathrm{O}_{2}$ easily reacts with biosubstances to form other ROS. Therefore, in order to accurately detect $\mathrm{H}_{2} \mathrm{O}_{2}$, the methods require a fast response time. Last but most important, there are many ROS with high reactivity coexisting in the living system which can interfer the detection of $\mathrm{H}_{2} \mathrm{O}_{2}$. Thus, high selectivity is also expected to be achieved for detection of $\mathrm{H}_{2} \mathrm{O}_{2}$. Therefore, detection of $\mathrm{H}_{2} \mathrm{O}_{2}$ with spatialtemporal accuracy is of great significance for mechanistic studies of $\mathrm{H}_{2} \mathrm{O}_{2}$-related biology.

Fluorescence imaging based on small-molecule fluorescent probes has emerged as an efficient methodology to visualize the spatial and temporal distribution of biomolecules in biological specimens due to its real-time, sensitive, and noninvasive characteristics. ${ }^{9-11}$ Up to now, numerous fluorescent probes for endogenous $\mathrm{H}_{2} \mathrm{O}_{2}$ detection that have been elaborated, ${ }^{\mathbf{1 2 - 1 6}}$ and the detection mechanisms of these $\mathrm{H}_{2} \mathrm{O}_{2}$ probes are mainly based on boronate oxidation ${ }^{\mathbf{1 7}}$ or Baeyer-Villiger-type reactions. ${ }^{18}$ To some extent, these probes always have some minor defects. Several boronate-based probes react more slowly with $\mathrm{H}_{2} \mathrm{O}_{2}$ compared to other reactive species (e.g., peroxynitrite and hypochlorite). ${ }^{19-21}$ Some of them have been used to detect peroxynitrite $^{22-24}$ or benzoyl peroxide ${ }^{25}$ instead of $\mathrm{H}_{2} \mathrm{O}_{2}$. On the other hand, the vast majority of these probes are intensity-based turn-on fluorescent probes. ${ }^{26}$ However, interpretation of the results obtained with turn-on probes could be complex. As the fluorescence intensity is very sensitive to environmental factors such as probe concentration, temperature, medium polarity, and $\mathrm{pH}$ and also instrumental set-ups, such intensity-based 
probes are not suitable for quantitative analysis. In this context, ratiometric probes that have an internal correction capability are in great demand. Ratiometric probes provided two separate signals for the probe itself and for its reaction product with the analyte or its analyte bound form, which can normalize the interference. Thus, ratiometric probes with high response rate, excellent selectivity, and good sensitivity should be developed for fulfilling the stringent issues of biological examination.

To address this issue, we herein report a novel ratiometric fluorescent probe JNY-1 (Scheme 1) for detection of $\mathrm{H}_{2} \mathrm{O}_{2}$ with high selectivity and sensitivity. In this work, we choose an integration of fluorescein and coumarin fluorophores as the fluorogen because of its' tunable fluorescent properties which could be used for design ratiometric response probes. The pentafluorobenzenesulfonyl group was selected as the reaction unit. As we all known, it is more stable to hydrolysis than ester bond, and the pentafluorobenzene ring enhances the reactivity of the sulfonates toward $\mathrm{H}_{2} \mathrm{O}_{2}$, which can contribute to enhance the selectivity and sensitivity of probe towards to $\mathrm{H}_{2} \mathrm{O}_{2} \cdot{ }^{27}$. As shown in Fig. 1, in the absent of $\mathrm{H}_{2} \mathrm{O}_{2}$, probe JNY-1 is present in spirocyclic form only with coumarin-like emission. After selectively deprotecting the pentafluorobenzenesulfonyl group by $\mathrm{H}_{2} \mathrm{O}_{2}$, probe JNY-1 is present in its strongly fluorescent quinoid form and the fluorescence shift from $440 \mathrm{~nm}$ (coumarin-like emission) to $540 \mathrm{~nm}$ (fluorescein-like emission).

\section{Results and discussion}

The synthetic route of probe JNY-1 is shown in Scheme 1. First, an aldehyde-functionalized fluorescein was prepared according to previous reports. ${ }^{28,29}$ The further reaction of fluorescein monoaldehyde with diethyl malonate afforded a coumarin hybrid 1, which can be treated with 2,3,4,5,6pentafluorobenzene-1-sulfonyl chloride, eventually resulting in the formation of probe JNY-1, which was characterized by ${ }^{1} \mathrm{H}$, ${ }^{13} \mathrm{C}$ NMR and mass spectra.

With the probe JNY-1 in hand, we then tested its spectroscopic properties. The fluorescence and absorption spectra were measured in DMF/phosphate buffer ( $30: 70 \mathrm{v} / \mathrm{v}, 10 \mathrm{mM}, \mathrm{pH}$ 7.4) system at room temperature $\left(25^{\circ} \mathrm{C}\right)$. As displayed in Fig. $1 \mathrm{~b}$, the probe JNY-1 itself showed the maximal absorbance centered at $340 \mathrm{~nm}$. With the excitation at $340 \mathrm{~nm}$, the probe JNY-1 offered fluorescence emission centered at $440 \mathrm{~nm}$, which is belong to coumarin-like emission. Upon the addition of $\mathrm{H}_{2} \mathrm{O}_{2}$, the
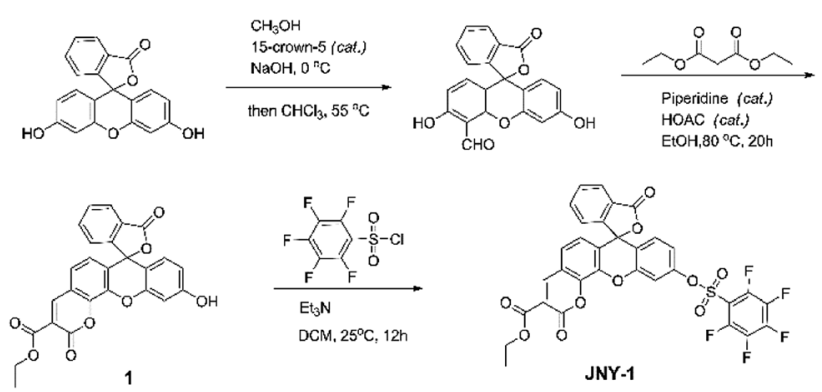

Scheme 1 The synthsize route of probe JNY-1.

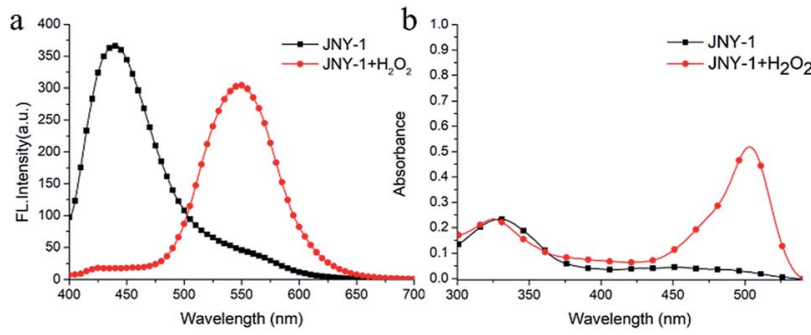

Fig. 1 Fluorescence (a) and UV/Vis absorption (b) spectra of JNY-1 (10 $\mu \mathrm{M})$ in the absence and presence of $\mathrm{H}_{2} \mathrm{O}_{2}(100 \mu \mathrm{M})$.

reaction of JNY-1 and $\mathrm{H}_{2} \mathrm{O}_{2}$ happened and resulted the dissociation of the pentafluorobenzenesulfonyl group from JNY-1. Obviously, this detection process is not reversible. Thus, a new absorbance centered at $480 \mathrm{~nm}$ emerged. Correspondingly, the fluorescein-like emission centered at $540 \mathrm{~nm}$ was observed.

As shown in Fig. 2, the time course of the fluorescent emission of probe JNY-1 $(10 \mu \mathrm{M})$ at $540 \mathrm{~nm}$ in the presence of $\mathrm{H}_{2} \mathrm{O}_{2}$ (10 equiv.) was studied. By examining the kinetic data for $\mathrm{H}_{2} \mathrm{O}_{2}$, it is apparent that it would take no more than 10 minutes to reach the equilibrium. Generally, it needs $30 \mathrm{~min}$ or more to reach the reaction equilibrium between arylboronate based probes and $\mathrm{H}_{2} \mathrm{O}_{2}$. JNY-1 showed faster response to $\mathrm{H}_{2} \mathrm{O}_{2}$ mainly due to the pentafluorobenzene ring enhances the reactivity of the sulfonates toward $\mathrm{H}_{2} \mathrm{O}_{2}$. The rapid response time is favorable for detection and imaging of $\mathrm{H}_{2} \mathrm{O}_{2}$ in the complex biological systems.

Next, the detailed emission titration experiments of probe JNY-1 $(10 \mu \mathrm{M})$ with various concentrations of $\mathrm{H}_{2} \mathrm{O}_{2}$ were also carried out in the DMF/phosphate buffer $(30: 70 \mathrm{v} / \mathrm{v}, 10 \mathrm{mM}, \mathrm{pH}$ 7.4) system. As shown in Fig. 3, when the probe JNY-1 was treated with different concentrations of $\mathrm{H}_{2} \mathrm{O}_{2}(0-200 \mu \mathrm{M})$, the emission band at $440 \mathrm{~nm}$ decreased progressively, while a new emission peak around $540 \mathrm{~nm}$ was observed. Importantly, as shown in Fig. 4 , the ratio of emission intensities $\left(I_{540 \mathrm{~nm}}: I_{440}\right.$

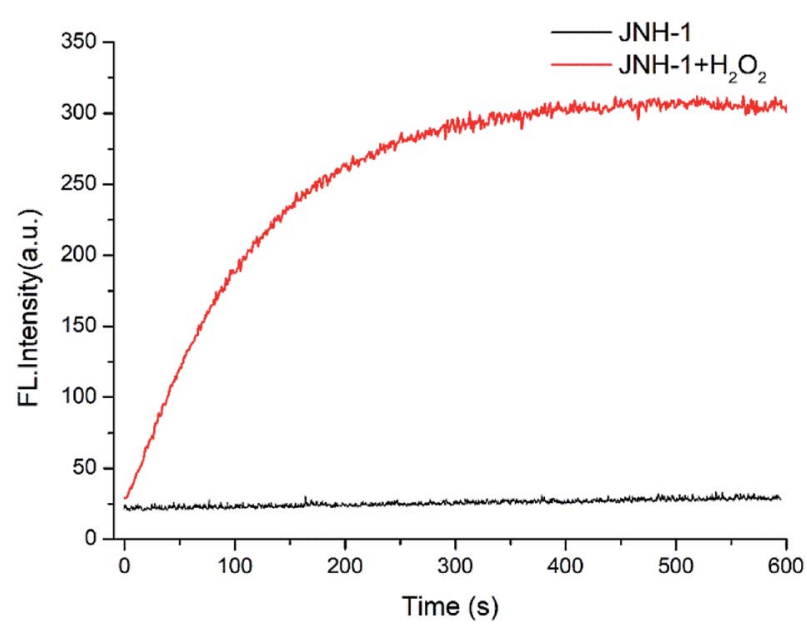

Fig. 2 The time course of the emission intensity of JNY-1 $(10 \mu \mathrm{M})$ at $540 \mathrm{~nm}$ in the presence and absence of $\mathrm{H}_{2} \mathrm{O}_{2}(100 \mu \mathrm{M})$ with $\lambda_{\mathrm{ex}}=$ $340 \mathrm{~nm}$. 


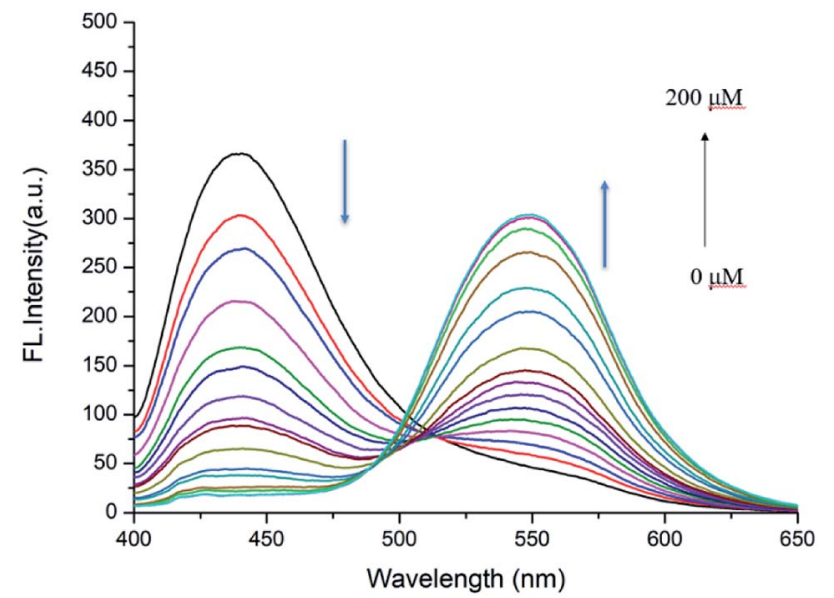

Fig. 3 Fluorescence responses of probe JNY-1 $(10 \mu \mathrm{M})$ toward different concentrations of $\mathrm{H}_{2} \mathrm{O}_{2}(0-200 \mu \mathrm{M})$ with $\lambda_{\mathrm{ex}}=380 \mathrm{~nm}$.

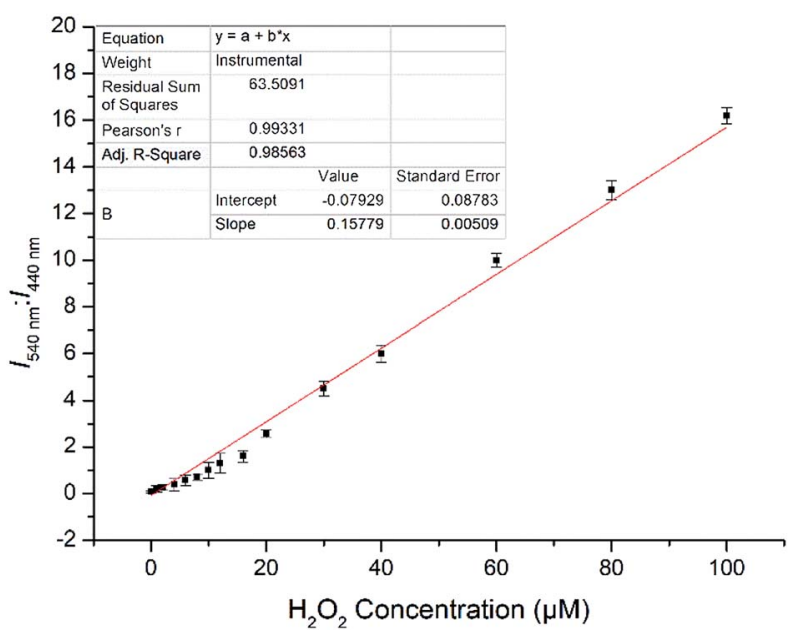

Fig. 4 Fluorescence intensity ratio $\left(I_{540 \mathrm{~nm}}: I_{440 \mathrm{~nm}}\right)$ of probe JNY-1 versus $\mathrm{H}_{2} \mathrm{O}_{2}$ concentration $(0-100 \mu \mathrm{M})$ with $\lambda_{\mathrm{ex}}=380 \mathrm{~nm}$, error bars, $\mathrm{SD}(n=3)$.

$\mathrm{nm}$ ) increased by nearly 180 -fold and exhibited good linear correlation with the amount of $\mathrm{H}_{2} \mathrm{O}_{2}\left(0-100 \mu \mathrm{M}, R^{2}=0.98563\right)$. The detection limit was calculated to be $0.08 \mu \mathrm{M}(3 S / m$, in which $S$ is the standard deviation of blank measurements, $n=11$, and $m$ is the slope of the linear equation). As shown in Fig. S4, $\dagger$ with addition of $\mathrm{H}_{2} \mathrm{O}_{2}(0-200 \mu \mathrm{M})$, the initial absorption peak centered at $340 \mathrm{~nm}$ decreased slightly, along with a simultaneous emergence of the red shifted new absorption peaks at $500 \mathrm{~nm}$. Correspondingly, JNY-1 displayed distinct color changes from colorless to orange, which could be easily observed by the naked eye (Fig. S6 $\dagger$ ).

To verify the selectivity of JNY-1 for $\mathrm{H}_{2} \mathrm{O}_{2}$, we also measured the ratiometric signals change upon addition of a panel of ROS, reactive nitrogen species (RNS), and the representative biological species. As shown in Fig. 5, only $\mathrm{H}_{2} \mathrm{O}_{2}$ could trigger a large ratiometric response. However, the ratiometric signals showed no or very minor changes for other species, including ${ }^{1} \mathrm{O}_{2}$,

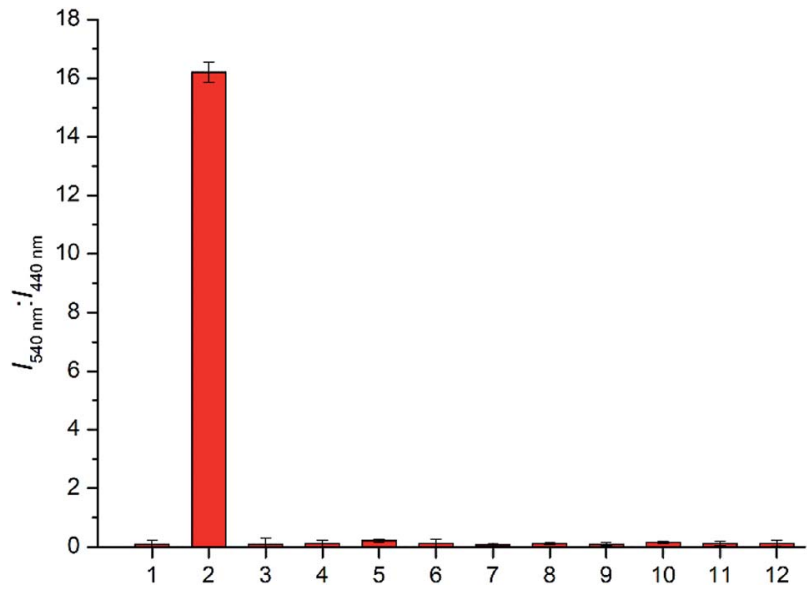

Fig. 5 Fluorescence responses $I_{540 \mathrm{~nm}}: I_{440 \mathrm{~nm}}$ of JNY-1 $(10 \mu \mathrm{M})$ with various analytes. (1) Free probe; (2) $\mathrm{H}_{2} \mathrm{O}_{2} ;(3){ }^{1} \mathrm{O}_{2} ;$ (4) $\mathrm{ONOO}^{-}$; (5) $\mathrm{NO}$;

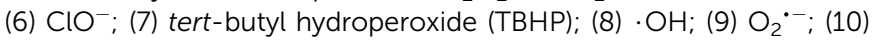
GSH; (11) ascorbic acid and (12) glucose. Each spectrum was recorded at $10 \mathrm{~min}$ after the addition, error bars, SD $(n=3)$.

$\mathrm{ONOO}^{-}, \mathrm{NO}, \mathrm{ClO}^{-}$, tert-butyl hydroperoxide (TBHP), $\cdot \mathrm{OH}, \mathrm{O}_{2}{ }^{\cdot-}$. $\mathrm{GSH}$, ascorbic acid, and glucose. This result indicated that probe JNY-1 exhibited remarkably high selectivity for $\mathrm{H}_{2} \mathrm{O}_{2}$.

To further evaluate the ability of probe JNY-1 for detection of $\mathrm{H}_{2} \mathrm{O}_{2}$ in living cells, we conducted the cell imaging experiments. As shown in Fig. 6, the liver cancer HepG2 cells in group A and B were incubated with $10 \mu \mathrm{M}$ of JNY-1 at $37^{\circ} \mathrm{C}$ for $15 \mathrm{~min}$ before fluorescence imaging. Group A was the control and group B was added $100 \mu \mathrm{M}$ of $\mathrm{H}_{2} \mathrm{O}_{2}$. As described in Fig. 6A, HepG2 cells incubated with $10.0 \mu \mathrm{M}$ JNY-1 show fluorescence in blue channel, but there is negligible fluorescence signal through green channel. On the contrary, the probe-loaded cells appear clear cellular profiles with bright green fluorescence when treated with $100 \mu \mathrm{M} \mathrm{H}_{2} \mathrm{O}_{2}$ for $10 \mathrm{~min}$, the original fluorescence signal in the blue channel weakened accordingly. These imaging results indicate that JNY-1 shows pleasurable cellpermeability and could be applied in dual-color fluorescence imaging of intracellular $\mathrm{H}_{2} \mathrm{O}_{2}$.

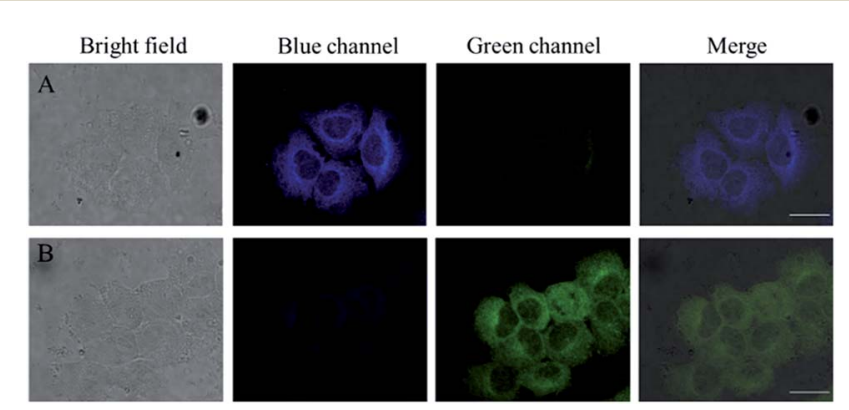

Fig. 6 Confocal fluorescence images of the liver cancer HepG2 cells with probe $\mathrm{JNH}-1$. Fluorescence images were obtained before and after incubation for 10 min without (A) or with (B) $100 \mu \mathrm{M} \mathrm{H}_{2} \mathrm{O}_{2}$. The images were collected at 425-465 nm (blue channel) and 520$560 \mathrm{~nm}$ (green channel) upon excitation at $405 \mathrm{~nm}$. Scale bar: $20 \mu \mathrm{m}$. 


\section{Conclusions}

In summary, we have described the design and synthesis of a new ratiometric fluorescent probe JNY-1 for detection of $\mathrm{H}_{2} \mathrm{O}_{2}$. The probe could selectively and sensitively respond to $\mathrm{H}_{2} \mathrm{O}_{2}$ within $10 \mathrm{~min}$ without interferences of other reactive oxygen species (ROS), reactive nitrogen species (RNS), and biologically relevant species. This probe was successfully applied for monitoring and imaging of $\mathrm{H}_{2} \mathrm{O}_{2}$ in liver cancer HepG2 cells under physiological conditions. The combination of ratiometric capability, sensitivity, specificity, and rapid response property makes the probe a candidate for various potential applications.

\section{Conflicts of interest}

There are no conflicts to declare.

\section{Acknowledgements}

This work was supported by the National Nature Science Foundation of China (No. 81701754 and 81601471), Provincial Natural Science Foundation of Hunan (No. 2019JJ40434) and Scientific Research Project of Hunan Health and Family Planning Commission (No. B20180048).

\section{Notes and references}

1 X. Chen, F. Wang, J. Y. Hyun, T. Wei, J. Qiang, X. Ren, I. Shin and J. Yoon, Chem. Soc. Rev., 2016, 45, 2976-3016.

2 W. Ahmad, B. Ijaz, K. Shabbiri, F. Ahmed and S. Rehman, J. Biomed. Sci., 2017, 24, 76.

3 H. K. Seitz and F. Stickel, Nat. Rev. Cancer, 2007, 7, 599-612. 4 S. Prasad, S. C. Gupta and A. K. Tyagi, Cancer Lett., 2017, 387, 95-105.

5 S. G. Rhee, Science, 2006, 312, 1882-1883.

6 I. Levitan, S. Volkov and P. V. Subbaiah, Antioxid. Redox Signaling, 2010, 13, 39-75.

7 S. Kanvah, J. Joseph, G. B. Schuster, R. N. Barnett, C. L. Cleveland and U. Landman, Acc. Chem. Res., 2010, 43, 280-287.

8 S. G. Rhee, T. S. Chang, Y. S. Bae, S. R. Lee and S. W. Kang, J. Am. Soc. Nephrol., 2003, 14, S211-S215.

9 J. Chan, S. C. Dodani and C. J. Chang, Nat. Chem., 2012, 4, 973-984.

10 X. Chen, T. Pradhan, F. Wang, J. S. Kim and J. Yoon, Chem. Rev., 2012, 112, 1910-1956.

11 X. Li, X. Gao, W. Shi and H. Ma, Chem. Rev., 2014, 114, 590659.
12 M. Abo, Y. Urano, K. Hanaoka, T. Terai, T. Komatsu and T. Nagano, J. Am. Chem. Soc., 2011, 133, 10629-10637.

13 B. C. Dickinson, V. S. Lin and C. J. Chang, Nat. Protoc., 2013, 8, 1249-1259.

14 C. Yik-Sham Chung, G. A. Timblin, K. Saijo and C. J. Chang, J. Am. Chem. Soc., 2018, 140, 6109-6121.

15 W. Zhang, W. Liu, P. Li, F. Huang, H. Wang and B. Tang, Anal. Chem., 2015, 87, 9825-9828.

16 Y. Zhou, W. Pei, X. Zhang, W. Chen, J. Wu, C. Yao, L. Huang, H. Zhang, W. Huang, J. S. Chye Loo and Q. Zhang, Biomaterials, 2015, 54, 34-43.

17 T. B. Ren, W. Xu, W. Zhang, X. X. Zhang, Z. Y. Wang, Z. Xiang, L. Yuan and X. B. Zhang, J. Am. Chem. Soc., 2018, 140, 7716-7722.

18 X. Jiao, Y. Xiao, Y. Li, M. Liang, X. Xie, X. Wang and B. Tang, Anal. Chem., 2018, 90, 7510-7516.

19 X. Wu, X. X. Chen, B. N. Song, Y. J. Huang, W. J. Ouyang, Z. Li, T. D. James and Y. B. Jiang, Chem. Commun., 2014, 50, 13987-13989.

20 S. Y. Xu, X. Sun, H. Ge, R. L. Arrowsmith, J. S. Fossey, S. I. Pascu, Y. B. Jiang and T. D. James, Org. Biomol. Chem., 2015, 13, 4143-4148.

21 M. Reverte, A. Vaissiere, P. Boisguerin, J.-J. Vasseur and M. Smietana, ACS Sens., 2016, 1, 970-974.

22 X. Sun, Q. Xu, G. Kim, S. E. Flower, J. P. Lowe, J. Yoon, J. S. Fossey, X. Qian, S. D. Bull and T. D. J. C. S. James, Chem. Sci., 2014, 5, 3368-3373.

23 J. Zhang, Y. Li and W. Guo, Anal. Methods, 2015, 7, 48854888.

24 J. Zhou, Y. Li, J. Shen, Q. Li, R. Wang, Y. Xu and X. Qian, RSC Adv., 2014, 4, 51589-51592.

25 W. Chen, Z. Li, W. Shi and H. Ma, Chem. Commun., 2012, 48, 2809-2811.

26 J. Kim, J. Park, H. Lee, Y. Choi and Y. Kim, Chem. Commun., 2014, 50, 9353-9356.

27 G. Chen, Q. Fu, F. Yu, R. Ren, Y. Liu, Z. Cao, G. Li, X. Zhao, L. Chen, H. Wang and J. You, Anal. Chem., 2017, 89, 85098516.

28 W. Wang, O. Rusin, X. Xu, K. K. Kim, J. O. Escobedo, S. O. Fakayode, K. A. Fletcher, M. Lowry, C. M. Schowalter, C. M. Lawrence, F. R. Fronczek, I. M. Warner and R. M. Strongin, J. Am. Chem. Soc., 2005, 127, 15949-15958.

29 Z. X. Han, X. B. Zhang, Z. Li, Y. J. Gong, X. Y. Wu, Z. Jin, C. M. He, L. X. Jian, J. Zhang, G. L. Shen and R. Q. Yu, Anal. Chem., 2010, 82, 3108-3113. 